\title{
Risk Assessment of Agricultural Drought Disaster in Southern China
}

\author{
Zhi-Lan Wang, Jing Wang, and Jin-Song Wang \\ Lanzhou Institute of Arid Meteorology, China Meteorological Administration, Key Laboratory of Arid Climatic Change and \\ Reducing Disaster of Gansu Province and Key Laboratory of Arid Climate Change and Disaster Reduction of \\ China Meteorological Administration, Lanzhou 730020, China
}

Correspondence should be addressed to Zhi-Lan Wang; wangzhlan2008@163.com

Received 17 July 2015; Accepted 5 November 2015

Academic Editor: Yong-Ping Wu

Copyright (C) 2015 Zhi-Lan Wang et al. This is an open access article distributed under the Creative Commons Attribution License, which permits unrestricted use, distribution, and reproduction in any medium, provided the original work is properly cited.

Risk assessment of drought disaster is necessary for the sustained agriculture development under the background of global climate change, and, meanwhile, it is an urgent scientific issue needed to be solved in agricultural risk assessment discipline. In this paper, collecting the areas covered by drought disasters, areas affected by drought disasters, areas with no harvest by drought disasters, areas planted, and yield per unit area data, agricultural drought disasters losses of the southern five provinces in China were calculated. The best probability density function was obtained according to the goodness of fit test results. Then, the value at risk (VaR) from financial market risk research method was used to the effective measure of agricultural drought risk. The results show that, in southern five provinces of our research region, risk of agricultural drought disaster in Yunnan and Guizhou is greater than other three provinces. In the scenario of 50 years and 100 years for a return, the crop loss caused by drought will reach $13.6 \%$ and $17.4 \%$ in Yunnan province, and the crop loss will be more serious in Guizhou province and be up to $15.3 \%$ and $18.1 \%$. The above results can provide multifaceted information about drought risk that can help to guide management of drought disasters.

\section{Introduction}

Drought is one of the most serious natural disasters in the world, which cause a large amount of economic loss. The frequency of drought event increased in the past few decades under global climate [1]. Furthermore, these events caused devastation and far-reaching consequences to agriculture, economy, water availability, and society. The risk assessment of drought disaster plays an important role on setting an actuarial premium of crop insurance contacts, which have effects on the government policies (e.g., drought disaster prevention and reduction and cropping configuration optimization) (Zhang et al. 2004). Therefore, it is important to assess the severe impacts of drought disaster.

It is essential to carry out natural disaster risk assessment prior to the definition of natural disaster risk. Huang et al. [2] suggested that the natural disaster risk is the future adverse event scenario of natural event as the main cause. Based on the risk origin, the core of natural disaster risk is "futuristic," "negativity," and "uncertainty" [3]. The approaches of risk assessment relate to the determination of index system, mathematics model, and the structure of standard system. In addition, assessment goal is to analyze the uncertainty of disaster losses in future. At present, the main approaches for disaster risk assessment have been classified from three different angles, that is, risk factors, risk loss, and risk mechanisms (Xu 2012). Drought risk assessment to agricultural production mainly used two approaches: climatic indices such as precipitation, evaporation, and crop simulation model in the early time [4-7]. With the coming of 21st century, drought disaster risk was considered the potential adverse effects of drought as a product of the frequency of drought, the spatial extent of damage caused by drought, and regional production level of crops from the viewpoints of climatology, disaster science, economics, environmental science, risk assessment, and so on [8], (Zhang et al. 2004); [9]. In recent years, the government has paid more attentions on drought disaster prevention and mitigation and risk management. Therefore, 
an accurate drought risk assessment is the foundation of government policy decision, which quantified the degree of hazard and vulnerability of the different regions [10].

Risk mainly refers to the possibility and loss degree of disaster which could occur in the next few years. Xu and Zhang [11] introduced an evaluation method for agricultural catastrophic risk based on the value at risk (VaR) from economics to realize precision measurement of agricultural catastrophe losses and showed the losses of the future adverse scenario in Henan province of China. In the last decade, the frequency of extreme drought event rose in the semiarid and humid region of China. For instance, the summer in 2006 [12], the autumn in 2009 to the spring in 2010 [13], the late summer in 2011 [14] in southwest China, and these disaster events caused serious economic losses. However, there is little research done about drought disaster risk assessment in southern China. Therefore, it is necessary to assess drought disaster risk of southern China. In this study, drought disaster risk is considered the probability in the future adverse senior of crop losses, and risk assessment in five provinces (Sichuan, Yunnan, Guizhou, Guangxi, and Guangdong) is discussed. In Section 2, we describe data and methods. Section 3 presents the results, while the main conclusions and discussions are summarized in Section 4.

\section{Data and Methods}

2.1. Data. The yearly areas covered by drought disasters, areas affected by drought disasters, areas with no harvest by drought disasters, areas planted, and yield per unit area data from 1978 to 2012 were collected. These were all from the Ministry of Agriculture Planting Industry Management (MAPIM, http://www.zzys.moa.gov.cn/).

The study areas cover Sichuan, Yunnan, Guizhou, Guang$\mathrm{xi}$, and Guangdong provinces, as illustrated in Figure 1. In this area the terrain is complex and the topography is characterized by higher in the west and lower in the east. Most areas belong to the humid and semihumid climate zone. On the whole, the precipitation of the study area increases from the northwest to the southeast.

The mean annual precipitation varies from about $500 \mathrm{~mm}$ in the northwest in Sichuan province to more than $2,000 \mathrm{~mm}$ in Guangxi and Guangdong provinces along the south coast of China. It is worth noting that there is a high value area of precipitation in the central part of Sichuan province, where Emei Mountain is located, due to the mountain precipitation effect. Drought hazards occur frequently in the study area, with one distinction feature in recent years that droughts generally extend over a large area and they can continue for months or years, causing serious and lasting impacts on society and economy.

\subsection{Approach}

2.2.1. Agricultural Drought Disaster Loss Model. Crop drought loss is the key point of the research, which at present cannot be directly obtained due to drought disasters statistics from the Ministry of Civil Affairs in China. According to the previous study, the loss model of agricultural drought disaster based on indirect drought disaster statistics data is shown:

$$
\begin{aligned}
& \text { Grain }_{\text {Loss }(i)} \\
& =\frac{\left\{\left[\left(A_{1}-A_{2}\right) \times C_{1}+\left(A_{2}-A_{3}\right) \times C_{2}+A_{3} \times C_{3}\right] \times y\right\}}{\left[A_{0} \times y\right]},
\end{aligned}
$$

where Grain $_{\text {Loss }(i)}$ is the grain loss rate caused by drought disasters in year $i ; A_{1}, A_{2}$, and $A_{3}$ are, respectively, the crop area covered by drought disasters, the crop area affected by drought disasters, and the crop area with no harvest by drought disasters in year $i ; C_{1}, C_{2}$, and $C_{3}$ are coefficients of yield reduction in the crop area covered by drought disasters, the crop area affected by drought disasters, and the crop area with no harvest by drought disasters; $y$ denotes the crop yield per hectare in year $i$; $A_{0}$ denotes the total crop sown hectares [11].

The area covered by drought disasters, area affected by drought disasters, and area with no harvest by drought disasters are defined as the number of hectares with $10 \%-$ $30 \%, 30 \%-80 \%$, and over $80 \%$ damage. The median of number of hectares with damage of $C_{1}, C_{2}$, and $C_{3}$ is 0.20 , 0.55 , and 0.90 , respectively.

\subsubsection{The Probability Distribution Model of Agricultural} Drought Disaster. The main purpose of the agricultural drought risk assessment is to obtain the possibility of grain loss caused by drought under various intensities, which is the probability density function (PDF). Therefore, how to choose reasonable probability density function of crop drought losses is the key issue in this paper.

Based on above considerations, we choose 11 kinds of probability distribution models that are Beta, Chi-square, Fréchet, Gamma, Weibull, Generalized Extreme Value, Generalized Pareto, Logistic, Log-Logistic, Normal, and Lognormal distribution models. Firstly, the crop yield losses are assumed to obey these candidate models, and then Anderson-Darling (A-D) test, Kolmogorov-Smirnov (K-S) test, and Chi-square $\left(\chi^{2}\right)$ test are used to select the best model. Due to the differences between three kinds of test methods, the results may be different. In this study, if all three or two of three test results are consistent, we are subject to the results; if the three test results are not the same, we average the ranking of results.

The optimal model is selected from 11 candidate models, and then maximum likelihood method or linear-moment method is used to estimate parameters of the optimal model to get the PDF. And then, the charts of density plot, probability plot, and return level plot are analyzed to test the accuracy of the optimal model further.

2.2.3. Agricultural Drought Disaster Risk Measure. This paper uses the mainstream of the current financial market risk measurement methods: value at risk (VaR) to effectively measure agricultural drought risk. The definition of $\mathrm{VaR}$ is called the maximum possible loss $x$ in the coming given period when given the normal financial market conditions 


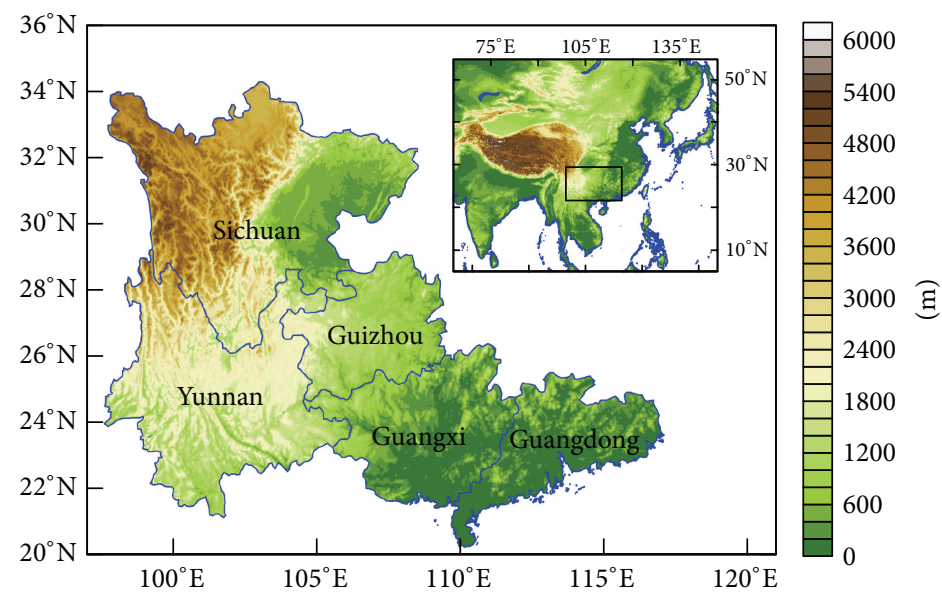

FIGURE 1: Study domain with topography (m).

and a certain confidence level $\alpha$. That is to say, VaR in the given probability is actually the maximum possible loss of portfolio in holding period, which is the suffered risk degree. Mathematical definition is that $x$ is random variable to describe portfolio loss, with probability distribution function $F(x)$, given a confidence level $\alpha \in(0,1)$, and then

$$
\operatorname{VaR}(\alpha)=\max \left\{\frac{x}{F(x)} \geq \alpha\right\}
$$

The basic formula can be shown as follows:

$$
P(\Delta X>\mathrm{VaR})=1-\alpha,
$$

where $P$ is the probability of the portfolio loss, $\Delta X$ is the loss of portfolio in the holding period, and VaR is the value at risk under confidence level $\alpha$. With a given confidence level and the holding period, $\mathrm{VaR}$ is practical significance.

In this paper, $\mathrm{VaR}$ is the value at the drought disasters risk. According to the optimal model for PDF of agricultural drought loss, VaR was calculated by the upper quartile of $F(x)$, given the scenario of suffering agricultural drought disaster of 10 years $(\alpha=0.1), 20$ years $(\alpha=0.05), 50$ years $(\alpha=0.02)$, and 100 years $(\alpha=0.01)$ for a return.

\section{Results}

3.1. Interannual Variation of the Agricultural Drought Disaster Loss Rate. Based on indirect drought disaster statistical data and agricultural drought disaster loss model, agricultural drought disaster loss rates in the five southern provinces are obtained. Variations of the loss rate from 1978 to 2012 are shown in Figure 2. The loss rates distinctly fluctuated in five provinces. The average annual loss rate of Yunnan and Guizhou provinces showed more severe loss by drought disasters than the other three provinces, and the drought disaster losses fluctuate strongly in nearly a decade. The figure shows suffering serious drought in southern China severe losses of Yunnan in 2010, Guizhou in 2010 and 2011. The drought disaster losses of Sichuan province were relatively small in recent 5 years. The severe drought loss during 1988

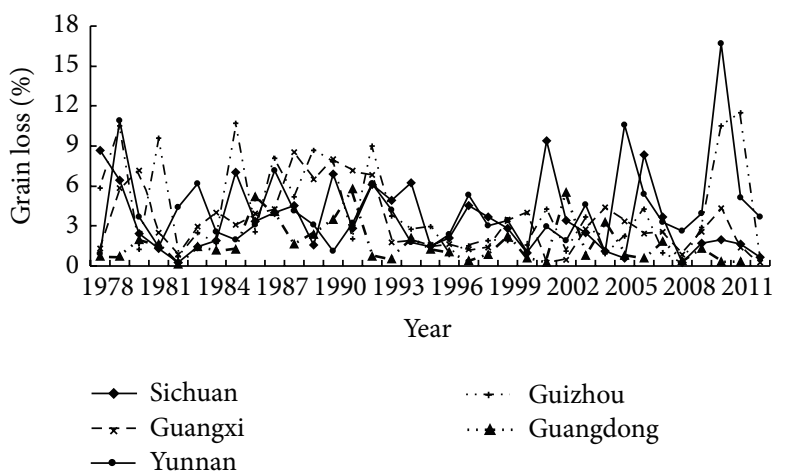

FIGURE 2: Variations of agricultural drought disaster loss rate in five provinces from 1978 to 2012.

TABLE 1: Statistical indicators of grain loss rate.

\begin{tabular}{lccccc}
\hline Province & $\begin{array}{c}\text { Mean } \\
(\%)\end{array}$ & $\begin{array}{c}\text { Median } \\
(\%)\end{array}$ & $\begin{array}{c}\text { Standard } \\
\text { deviation }\end{array}$ & Skewness & Kurtosis \\
\hline Yunnan & 4.13 & 3.31 & 3.20 & 2.27 & 6.49 \\
Guizhou & 4.18 & 2.73 & 3.52 & 0.87 & -0.68 \\
Sichuan & 3.45 & 2.80 & 2.54 & 0.83 & -0.27 \\
Guangxi & 3.31 & 2.78 & 2.30 & 0.77 & -0.31 \\
Guangdong & 1.67 & 1.23 & 1.54 & 1.52 & 1.57 \\
\hline
\end{tabular}

to 1992 in Guangxi province is shown. The drought loss was relatively small in Guangdong province, just over 5\% in 1986, 1991, and 2002.

3.2. PDF of the Agricultural Drought Disaster Loss Rate. Table 1 shows some statistical indicators of grain loss rate in five provinces. Grain loss rates in Yunnan and Guizhou are relatively severer than the other provinces, and their fluctuation of grain loss is relatively greater. The skewness is a measure of asymmetry and the kurtosis refers to the sharp curve of the peak level. Distinctly, the grain loss rate distributions of five provinces all do not fit normal distribution. The skewness of all over five provinces is positive 
TABLE 2: Goodness of fit test for a series of grain losses from 1978 to 2012.

\begin{tabular}{|c|c|c|c|c|c|c|c|c|}
\hline \multicolumn{9}{|c|}{ Yunnan province } \\
\hline & \multirow{2}{*}{ Distribution } & \multicolumn{2}{|c|}{ K-S test } & \multicolumn{2}{|c|}{ A-D test } & \multicolumn{2}{|c|}{$\chi^{2}$ test } & \multirow{2}{*}{ Overall rank } \\
\hline & & Statistic & Rank & Statistic & Rank & Statistic & Rank & \\
\hline 1 & Beta & 0.1764 & 8 & 5.202 & 10 & \multicolumn{2}{|c|}{$\mathrm{N} / \mathrm{A}$} & 10 \\
\hline 2 & Chi-square & 0.0877 & 2 & 0.4897 & 4 & 1.4903 & 5 & 5 \\
\hline 3 & Fréchet & 0.1764 & 9 & 1.0236 & 7 & 5.5586 & 7 & 7 \\
\hline 4 & Gamma & 0.1035 & 5 & 0.7546 & 6 & 2.2523 & 6 & 6 \\
\hline 5 & Gen. Extreme Value & 0.0963 & 4 & 0.2409 & 1 & 0.5478 & 2 & 1 \\
\hline 6 & Gen. Pareto & 0.1225 & 7 & 11.5120 & 11 & \multicolumn{2}{|c|}{ N/A } & 11 \\
\hline 7 & Log-Logistic & 0.1151 & 6 & 0.3036 & 3 & 0.5458 & 1 & 4 \\
\hline 8 & Logistic & 0.1774 & 10 & 1.8251 & 8 & 6.4070 & 8 & 8 \\
\hline 9 & Lognormal & 0.0894 & 3 & 0.2589 & 2 & 0.5592 & 3 & 2 \\
\hline 10 & Normal & 0.1833 & 11 & 2.1595 & 9 & 6.5536 & 9 & 9 \\
\hline 11 & Weibull & 0.0798 & 1 & 0.7311 & 5 & 0.7837 & 4 & 3 \\
\hline
\end{tabular}

Guizhou province

\begin{tabular}{|c|c|c|c|c|c|c|c|c|}
\hline & Distribution & & & & & Chi-s & test & Overall rank \\
\hline & & Statistic & Rank & Statistic & Rank & Statistic & Rank & \\
\hline 1 & Beta & 0.1562 & 8 & 1.5245 & 8 & 8.0286 & 11 & 8 \\
\hline 2 & Chi-square & 0.1588 & 9 & 1.6824 & 9 & 4.7667 & 9 & 9 \\
\hline 3 & Fréchet & 0.1187 & 4 & 1.0227 & 7 & 1.2168 & 3 & 4 \\
\hline 4 & Gamma & 0.1210 & 6 & 0.5784 & 5 & 3.4291 & 5 & 5 \\
\hline 5 & Gen. Extreme Value & 0.1264 & 7 & 0.7660 & 6 & 3.1980 & 4 & 7 \\
\hline 6 & Gen. Pareto & 0.1039 & 1 & 0.4822 & 3 & 4.5855 & 8 & 3 \\
\hline 7 & Log-Logistic & 0.1046 & 2 & 0.4324 & 2 & 0.4519 & 2 & 2 \\
\hline 8 & Logistic & 0.2278 & 11 & 2.3193 & 11 & 5.6073 & 10 & 11 \\
\hline 9 & Lognormal & 0.1091 & 3 & 0.3650 & 1 & 0.1562 & 1 & 1 \\
\hline 10 & Normal & 0.2108 & 10 & 2.0419 & 10 & 3.9747 & 7 & 10 \\
\hline 11 & Weibull & 0.1209 & 5 & 0.5180 & 4 & 3.6622 & 6 & 6 \\
\hline
\end{tabular}

Sichuan province

\begin{tabular}{|c|c|c|c|c|c|c|c|c|}
\hline & \multirow{2}{*}{ Distribution } & \multicolumn{2}{|c|}{ K-S test } & \multicolumn{2}{|c|}{ A-D test } & \multicolumn{2}{|c|}{ Chi-square test } & \multirow{2}{*}{ Overall rank } \\
\hline & & Statistic & Rank & Statistic & Rank & Statistic & Rank & \\
\hline 1 & Beta & 0.1425 & 8 & 4.8683 & 11 & \multicolumn{2}{|c|}{ N/A } & 11 \\
\hline 2 & Chi-square & 0.1208 & 7 & 0.8607 & 7 & 1.5898 & 6 & 7 \\
\hline 3 & Fréchet & 0.1553 & 10 & 1.6055 & 10 & 3.0417 & 8 & 9 \\
\hline 4 & Gamma & 0.0898 & 5 & 0.2768 & 3 & 1.4756 & 5 & 4 \\
\hline 5 & Gen. Extreme Value & 0.0897 & 4 & 0.2976 & 4 & 2.0143 & 7 & 6 \\
\hline 6 & Gen. Pareto & 0.0724 & 1 & 0.2087 & 1 & 0.1338 & 1 & 1 \\
\hline 7 & Log-Logistic & 0.0985 & 6 & 0.5200 & 6 & 0.2385 & 2 & 5 \\
\hline 8 & Logistic & 0.1572 & 11 & 1.2122 & 9 & 3.5754 & 10 & 10 \\
\hline 9 & Lognormal & 0.0842 & 3 & 0.4174 & 5 & 0.2948 & 3 & 3 \\
\hline 10 & Normal & 0.1442 & 9 & 1.0566 & 8 & 3.1526 & 9 & 8 \\
\hline 11 & Weibull & 0.0794 & 2 & 0.2112 & 2 & 0.9272 & 4 & 2 \\
\hline \multicolumn{9}{|c|}{ Guangxi province } \\
\hline & \multirow{2}{*}{ Distribution } & \multicolumn{2}{|c|}{ K-S test } & \multicolumn{2}{|c|}{ A-D test } & \multicolumn{2}{|c|}{$\chi^{2}$ test } & \multirow{2}{*}{ Overall rank } \\
\hline & & Statistic & Rank & Statistic & Rank & Statistic & Rank & \\
\hline 1 & Beta & 0.2046 & 11 & 1.6791 & 9 & 6.1571 & 10 & 11 \\
\hline 2 & Chi-square & 0.1443 & 8 & 0.8061 & 6 & 1.6388 & 4 & 6 \\
\hline 3 & Fréchet & 0.2020 & 10 & 2.1161 & 10 & 3.8613 & 9 & 10 \\
\hline 4 & Gamma & 0.0773 & 2 & 0.3536 & 3 & 1.6318 & 3 & 3 \\
\hline 5 & Gen. Extreme Value & 0.0751 & 1 & 0.2642 & 1 & 0.1700 & 1 & 1 \\
\hline 6 & Gen. Pareto & 0.0914 & 4 & 7.6277 & 11 & \multicolumn{2}{|c|}{ N/A } & 9 \\
\hline
\end{tabular}


TABLe 2: Continued.

\begin{tabular}{lclllllll}
\hline 7 & Log-Logistic & 0.1463 & 9 & 0.7665 & 5 & 3.8547 & 8 & 8 \\
8 & Logistic & 0.1259 & 6 & 1.0020 & 8 & 3.3282 & 7 & 7 \\
9 & Lognormal & 0.1302 & 7 & 0.6483 & 4 & 2.6984 & 6 & 4 \\
10 & Normal & 0.1207 & 5 & 0.9180 & 7 & 2.4136 & 5 & 5 \\
11 & Weibull & 0.0883 & 3 & 0.2875 & 2 & 0.5660 & 2 & 2 \\
\hline
\end{tabular}

Guangdong province

\begin{tabular}{|c|c|c|c|c|c|c|c|c|}
\hline & \multirow{2}{*}{ Distribution } & \multicolumn{2}{|c|}{ K-S test } & \multicolumn{2}{|c|}{ A-D test } & \multicolumn{2}{|c|}{ Chi-square test } & \multirow{2}{*}{ Overall rank } \\
\hline & & Statistic & Rank & Statistic & Rank & Statistic & Rank & \\
\hline 1 & Beta & 0.1609 & 8 & 1.5656 & 7 & 8.5130 & 9 & 10 \\
\hline 2 & Chi-square & 0.3638 & 11 & 8.5133 & 11 & 16.3110 & 10 & 11 \\
\hline 3 & Fréchet & 0.1308 & 7 & 0.6908 & 6 & 0.9239 & 3 & 4 \\
\hline 4 & Gamma & 0.0771 & 3 & 0.3632 & 4 & 1.7721 & 5 & 3 \\
\hline 5 & Gen. Extreme Value & 0.0860 & 6 & 0.2652 & 3 & 1.8178 & 6 & 6 \\
\hline 6 & Gen. Pareto & 0.0724 & 2 & 3.9815 & 10 & \multicolumn{2}{|c|}{ N/A } & 7 \\
\hline 7 & Log-Logistic & 0.0789 & 4 & 0.2173 & 2 & 0.1448 & 1 & 2 \\
\hline 8 & Logistic & 0.1911 & 10 & 2.1509 & 8 & 4.1516 & 8 & 8 \\
\hline 9 & Lognormal & 0.0596 & 1 & 0.1545 & 1 & 0.9238 & 2 & 1 \\
\hline 10 & Normal & 0.1837 & 9 & 2.2542 & 9 & 3.8282 & 7 & 9 \\
\hline 11 & Weibull & 0.0811 & 5 & 0.4925 & 5 & 1.7007 & 4 & 5 \\
\hline
\end{tabular}

values and it indicates the skewness to the right. The kurtosis of Yunnan and Guangdong is positive values, and it indicates that the grain loss distribution has a sharper peak, thinner shoulders, and fatter tails than the normal distribution. On the contrary, the distribution of Guizhou, Sichuan, and Guangxi has a flatter peak, fatter shoulders, and thinner tails.

Easy-Fit statistical software was used to estimate the parameter in optimal probability distribution model of grain loss data. Table 2 shows the results of A-D, K-S, and $\chi^{2}$ tests for the 11 kinds of probability distribution models. The optimal models are the Generalized Extreme Value model for Yunnan and Guangxi provinces, the Generalized Pareto for Sichuan province, and the Lognormal for Guizhou and Guangdong provinces.

Figure 3 shows the curves of PDF and the empirical frequencies of drought disaster loss rate for five provinces. It is evident that the distributions adapt well to the empirical frequencies of loss rate. According to the L-moment procedure, parameters of the distribution can be obtained. Table 3 shows the cumulative distribution functions of drought disaster loss rate for five provinces.

3.3. Risk Measure of Agricultural Drought Disaster Loss Rate. After obtaining cumulative distribution function of grain loss caused by drought in five provinces, VaR method is applied to assess drought disaster risk, given the various scenarios when suffering agricultural drought event of 10 years, 20 years, 50 years, and 100 years for a return (Table 4). For the severe droughts which are in the scenario of 20 years for a return, grain losses caused by drought in Yunnan and Guizhou, respectively, are $10.0 \%$ and $13.2 \%$ and in Sichuan, Guangxi, and Guangdong are below $10 \%$, up to $8.7 \%$, $7.8 \%$, and $5.2 \%$, separately. However, for the extreme drought risk such as the scenario of 100 years for a return, the grain loss
TABLE 3: Cumulative distribution functions in southern five provinces.

\begin{tabular}{lc}
\hline Province & Cumulative distribution function \\
\hline Yunnan & $F(x)=\exp \left\{-\left[1+0.26926\left(\frac{x-2.6048}{1.6302}\right)\right]^{-(1 / 0.26926)}\right\}$ \\
\hline Guizhou & $F(x)=\frac{1}{2}+\frac{1}{2} \operatorname{erf}\left[\frac{\ln (x-1.0187)}{0.99366 \times \sqrt{2}}\right]$ \\
\hline Sichuan & $F(x)=1-\left[1+0.26469\left(\frac{x-0.22677}{4.0761}\right)\right]^{-(1 / 0.26469)}$ \\
\hline Guangxi $\quad F(x)=\exp \left\{-\left[1+0.03688\left(\frac{x-2.2027}{1.8036}\right)\right]^{-(1 / 0.03688)}\right\}$ \\
\hline Guangdong & $F(x)=\frac{1}{2}+\frac{1}{2} \operatorname{erf}\left[\frac{\ln (x-0.11806)}{0.92316 \times \sqrt{2}}\right]$ \\
\hline
\end{tabular}

caused by drought disaster in Yunnan and Guizhou is up to $17.4 \%$ and $18.1 \%$ and in Sichuan, Guangxi, and Guangdong it is about $10 \%$. This shows that, in southern five provinces of our research region, the risk of agricultural drought disaster in Yunnan and Guizhou is greater than other three provinces.

The most serious drought disaster occurred in 2009-2010 over the past 50 years in Yunnan province [13], with huge economic losses. Using the VaR method, we calculate $16.7 \%$ of grain losses in 2010 and up to 100 years for a return. It also shows that using VaR method to assess agricultural drought risk is reasonable.

\section{Conclusion and Discussion}

Risk mainly refers to the possibility and degree of disaster which could occur in the next several years. In this paper, a 


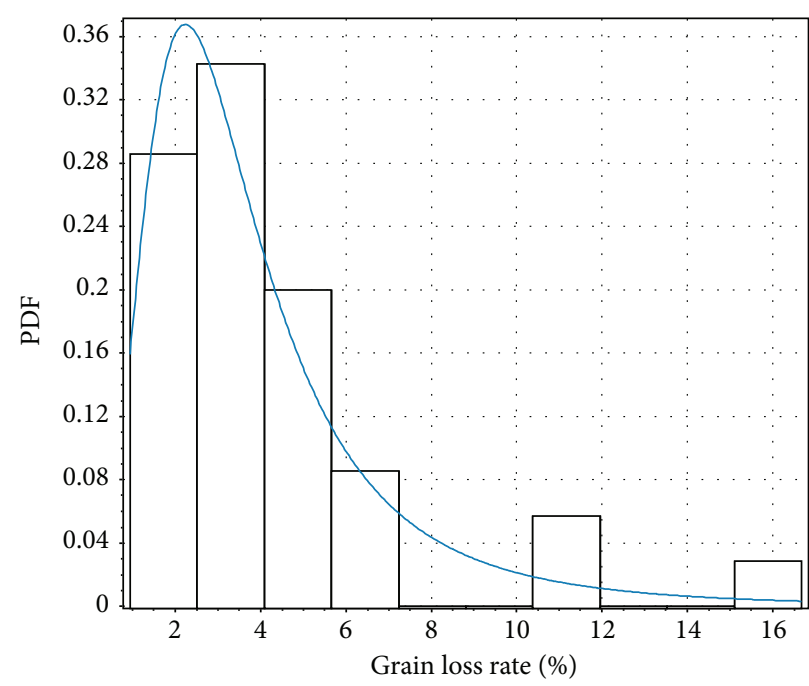

(a)

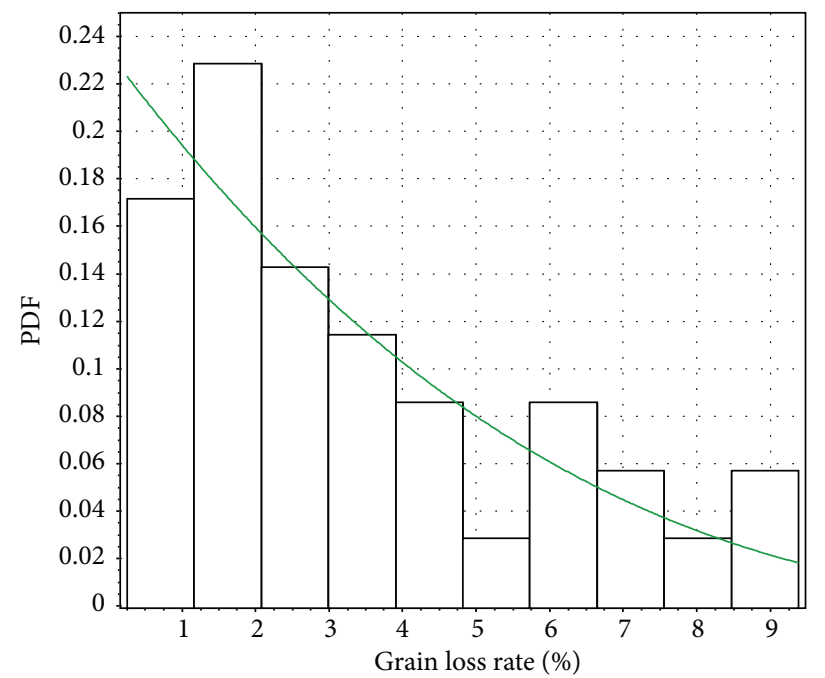

(c)

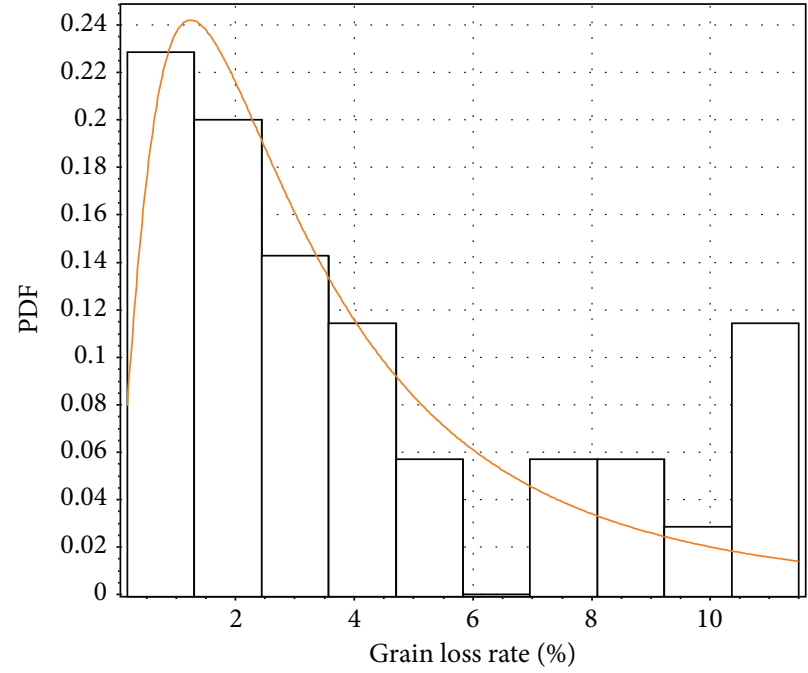

(b)

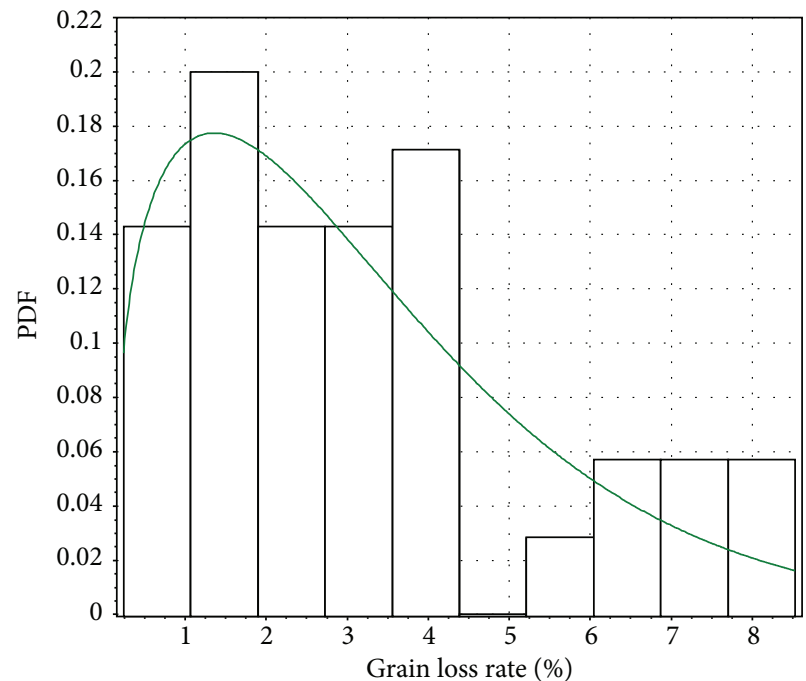

(d)

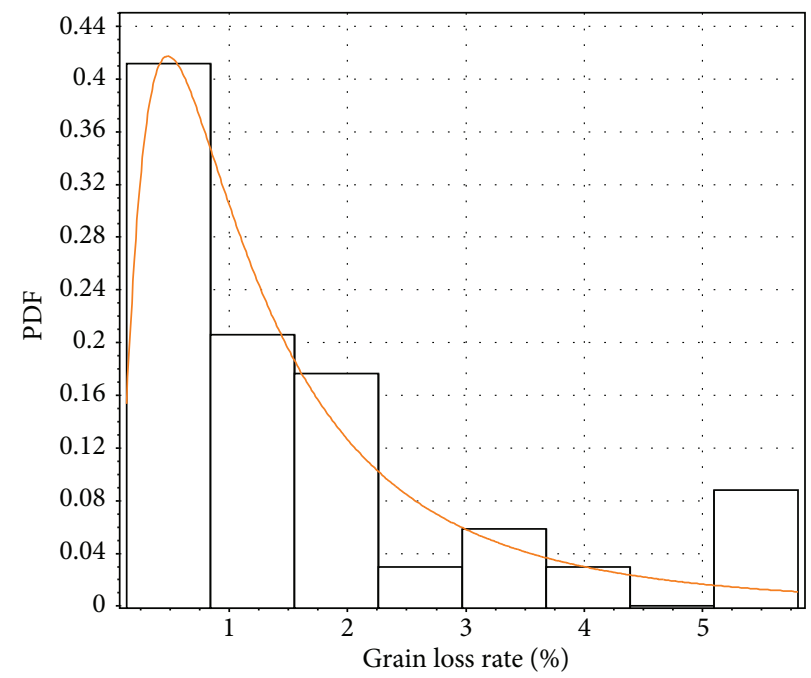

(e)

FIGURE 3: Probability density function (PDF) of agricultural drought disaster loss rate. (a) Yunnan, (b) Guizhou, (c) Sichuan, (d) Guangxi, and (e) Guangdong. 
TABLE 4: VaR of drought risk in southern five provinces.

\begin{tabular}{lcccc}
\hline Loss rate (\%) & 10 years for a return & 20 years for a return & 50 years for a return & 100 years for a return \\
\hline Yunnan & 7.7 & 10.0 & 13.6 & 17.4 \\
Guizhou & 6.9 & 13.2 & 15.3 & 18.1 \\
Sichuan & 7.3 & 8.7 & 10.2 & 11.1 \\
Guangxi & 6.4 & 7.8 & 9.8 & 11.3 \\
Guangdong & 3.7 & 5.2 & 7.5 & 9.5 \\
\hline
\end{tabular}

method of agricultural drought disaster risk assessment was introduced, which can be shown as the process of calculating crop loss by drought, fitting the best probability density function of crop loss rate, and analyzing the recurrence period of drought disasters. Based on the areas covered by drought disasters, areas affected by drought disasters, areas with no harvest by drought disasters, areas planted, and yield per unit area data from 1978 to 2012, the crop losses are calculated. According to the goodness of fitting, the best probability density function is selected from 11 kinds of probability distribution models. Then, the risk value was used to effectively measure the agricultural drought risk. Based on the framework for assessment, the following conclusions are provided:

(1) In terms of average annual loss rate, Yunnan and Guizhou provinces showed more severe loss by drought disasters than the other three provinces. Drought disaster losses fluctuate strongly in nearly a decade. Yunnan suffered heavy losses in 2010 and Guizhou province suffered severe losses in 2010 and 2011. From 2009 to 2011, a serious drought occurred in the southwest China.

(2) The optimal fitting model of the loss rate of agricultural drought disaster was Generalized Extreme Value (GEV) distribution model in Yunnan and Guangxi provinces, Generalized Pareto (GP) distribution model in Sichuan province, and Lognormal distribution model in Guizhou and Guangdong provinces.

(3) In the five southern provinces of China, agricultural drought disaster risk in Yunnan and Guizhou is greater than the other three provinces. Under the scenario of 50 years and 100 years for a return, the crop loss caused by drought will reach $13.6 \%$ and $17.4 \%$ in Yunnan province, and the crop loss will be more serious in Guizhou province and be up to $15.3 \%$ and $18.1 \%$.

The main purpose of agricultural drought risk assessment is to give the possibility under different intensities of drought and the traditional evaluation methods most based on the theory of normal distribution, but there may be a larger deviation using this method with frequent extreme disaster events. In this paper it is a highlight that from eleven kinds of probability distribution models the goodness of fit was selected. The limitation of this mathematical model is the length of history data. It is meaningful only when the samples are more than 30 . Based on the data, the risk of agricultural drought disaster was assessed at the provincial scale. If the drought disaster loss data of counties will be collected, risk assessment can be more detailed. Considering the different drought disaster-pregnant environment which includes climate background, underlying surface, land forms, soil, and river network, the transfer process of drought disaster was different and the crop losses caused by drought were different among different provinces [15].

Further research is directed to the more complex problem of agricultural catastrophic risk. To some extent, agricultural drought risk is the consequence of extreme weather events. However, agricultural drought risk is not the same as extreme weather risk. Other factors such as environment, water supply, agricultural investment, and farmer management should be taken into account. This means that the distribution for potential damage and losses after a certain type of extreme weather condition should be considered.

\section{Conflict of Interests}

The authors have declared that no conflict of interests exists.

\section{Acknowledgments}

The authors gratefully acknowledge funding from National Key Research and Development (973) Program of China 2013CB430206 and Public Welfare Industry (Meteorological) Research Special Major Projects GYHY201506001.

\section{References}

[1] L. Wang, W. Chen, and W. Zhou, "Assessment of future drought in Southwest China based on CMIP5 multimodel projections," Advances in Atmospheric Sciences, vol. 31, no. 5, pp. 1035-1050, 2014.

[2] C.-F. Huang, A.-L. Liu, and Y. Wang, "A discussion on basic definition of disaster risk," Journal of Natural Disasters, vol. 19, no. 6, pp. 8-16, 2010.

[3] C. Ni and J. Wang, "Further discussion on the definition of natural disaster risk," Journal of Catastrophology, vol. 27, no. 3, pp. 1-5, 2012 (Chinese).

[4] M. Lal, K. K. Singh, L. S. Rathore, G. Srinivasan, and S. A. Saseendran, "Vulnerability of rice and wheat yields in NW India to future changes in climate," Agricultural and Forest Meteorology, vol. 89, no. 2, pp. 101-114, 1998.

[5] C. T. Agnew, "Using the SPI to identify drought," Drought Network News, vol. 12, no. 1, pp. 6-12, 2000.

[6] C. F. Yamoah, D. T. Walters, C. A. Shapiro, C. A. Francis, and M. J. Hayes, "Standardized precipitation index and nitrogen 
rate effects on crop yields and risk distribution in maize," Agriculture, Ecosystems and Environment, vol. 80, no. 1-2, pp. 113-120, 2000.

[7] F. Ewert, D. Rodriguez, P. Jamieson et al., "Effects of elevated $\mathrm{CO}_{2}$ and drought on wheat: testing crop simulation models for different experimental and climatic conditions," Agriculture, Ecosystems \& Environment, vol. 93, no. 1-3, pp. 249-266, 2002.

[8] J. Q. Zhang, "Risk assessment of drought disaster in the maize-growing region of Songliao Plain, China," Agriculture, Ecosystems \& Environment, vol. 102, no. 2, pp. 133-153, 2004.

[9] G. M. Richter and M. A. Semenov, "Modelling impacts of climate change on wheat yields in England and Wales: assessing drought risks," Agricultural Systems, vol. 84, no. 1, pp. 77-97, 2005.

[10] S. M. Vicente-Serrano, S. Beguería, L. Gimeno et al., "Challenges for drought mitigation in Africa: the potential use of geospatial data and drought information systems," Applied Geography, vol. 34, no. 3, pp. 471-486, 2012.

[11] L. Xu and Q. Zhang, "Assessment approach for agricultural catastrophic risk in China," Scientia Agricultura Sinica, vol. 44, no. 9, pp. 1945-1952, 2011 (Chinese).

[12] J. B. Peng, Q. Y. Zhang, and C. Bueh, "On the characteristics and possible causes of a severe drought and heat wave in the Sichuan-Chongqing region in 2006," Climatic and Environmental Research, vol. 12, no. 3, pp. 464-474, 2007 (Chinese).

[13] R. H. Huang, Y. L. Liu, L. Wang, and L. Wang, "Analyses of the causes of severe drought occurring in Southwest China from the fall of 2009 to the spring of 2010," Chinese Journal of Atmospheric Sciences, vol. 36, no. 3, pp. 443-457, 2012 (Chinese).

[14] L. Sun, F. M. Ren, Z. Y. Wang et al., "Analysis of climate anomaly and cau-sation in August 2011," Meteorological Monthly, vol. 38, no. 5, pp. 615-622, 2011 (Chinese).

[15] J. S. Wang, Q. Zhang, S. P. Wang et al., "Characteristic analysis of drought disaster chain in southwest and south China," Journal of Arid Meteorology, vol. 33, no. 2, pp. 187-194, 2015 (Chinese). 


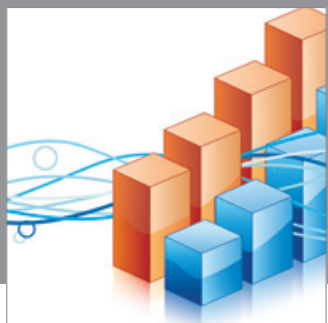

Advances in

Operations Research

mansans

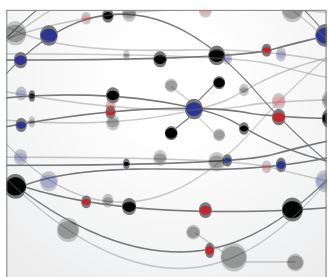

The Scientific World Journal
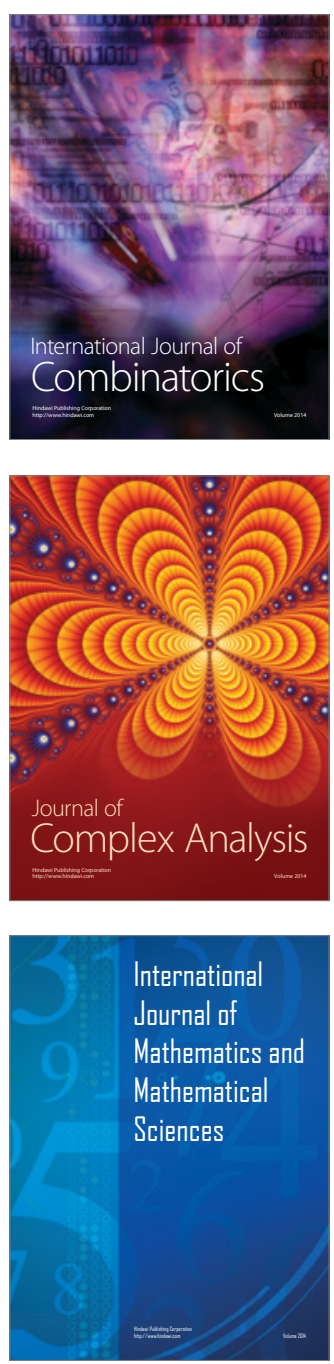
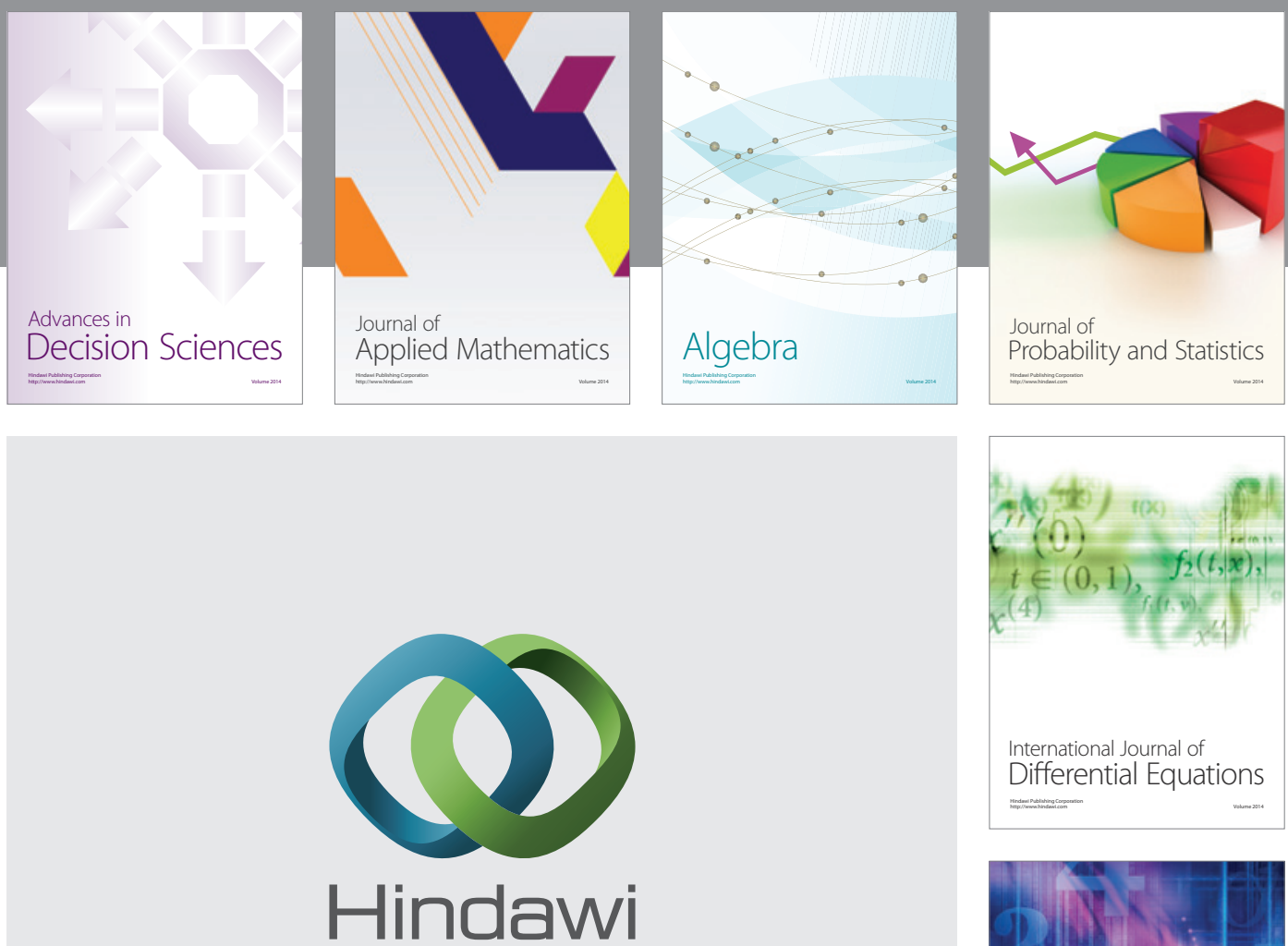

Submit your manuscripts at http://www.hindawi.com
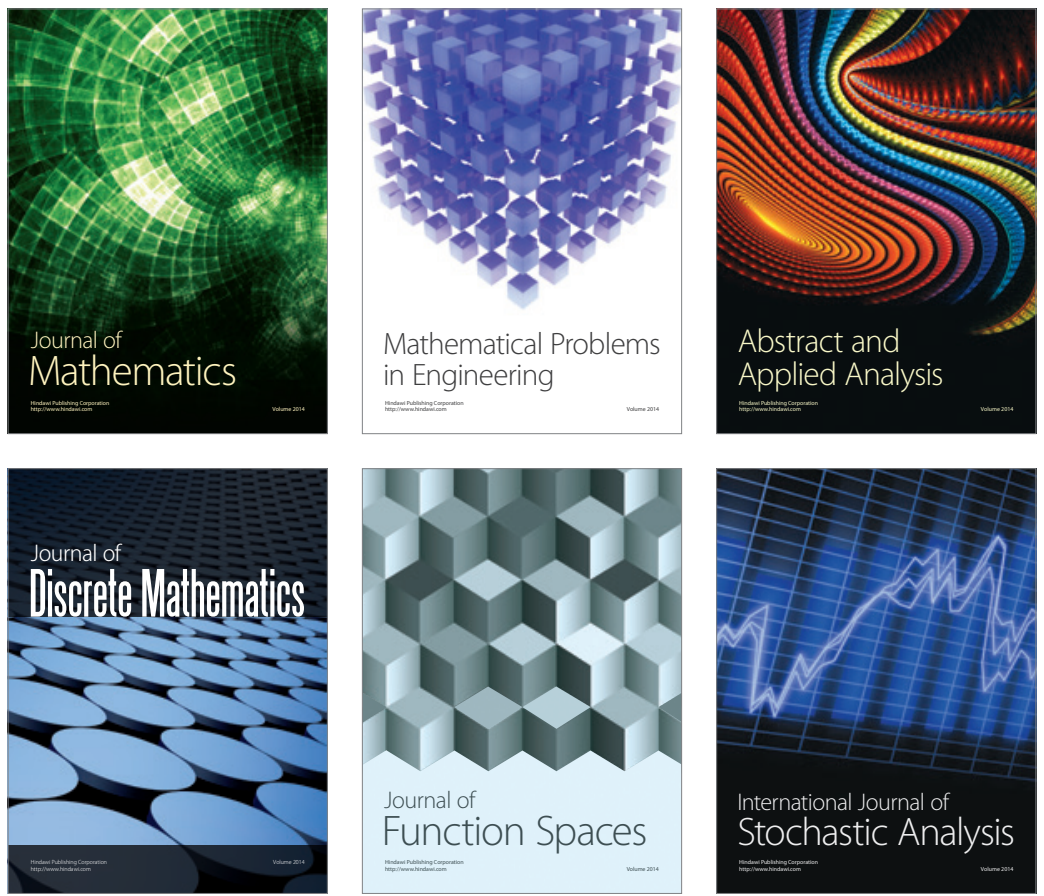

Journal of

Function Spaces

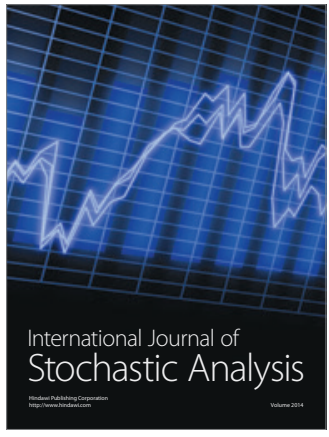

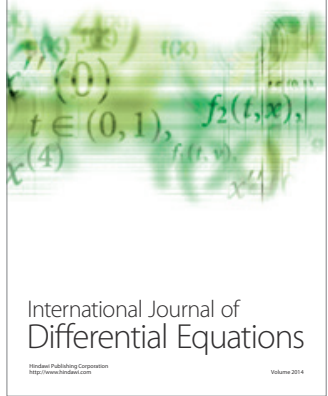
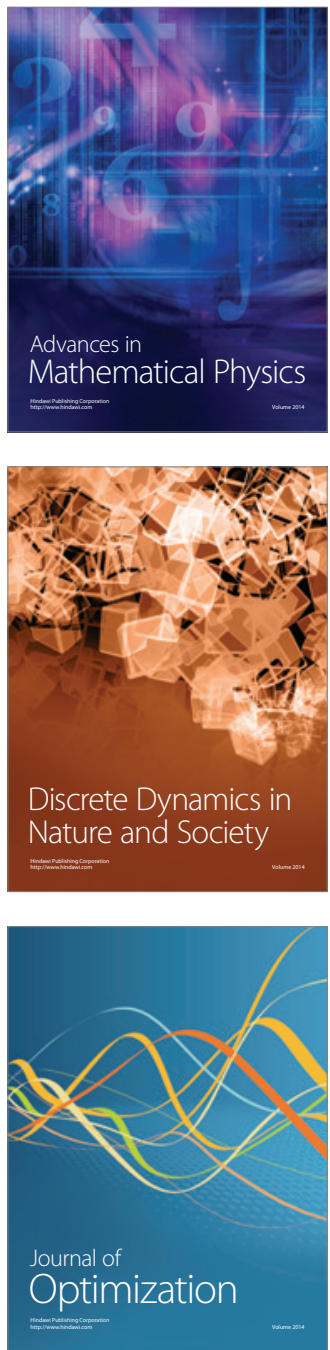